\title{
Ectopic Enterobius vermicularis
}

\author{
G. S. A. McDONALD AND D. O'B. HOURIHANE
}

From the Department of Pathology, Trinity College, Dublin, and the Federated Dublin Voluntary Hospitals

SUMmARY Enterobius vermicularis (the pinworm) commonly infests the lumen of the intestine but on rare occasions has been found in the wall or in the tissues outside the gastrointestinal tract. Three such patients have been encountered in whom Enterobius vermicularis was found in the wall of the colon, in the retrocaecal tissues, and on the peritoneum. The pathological lesions and their relationship to the clinical features are discussed. A brief review of the literature is given. It is concluded that Enterobius vermicularis can only penetrate the wall of the gastrointestinal tract if this is diseased. Once in the tissues the worms can cause an inflammatory reaction simulating carcinoma and Crohn's disease, and, by perforation of the intestine, cause a generalized peritonitis.

Enterobius vermicularis (pinworm or threadworm) is the most common worm infestation occurring in man (Swellengrebel and Sterman, 1961). The worms inhabit the lumen of the intestine in the region of the ileum, caecum, and appendix, and are said to be attached to the mucosa by their heads (Juniper, 1969; Faust and Russell, 1964). Their normal lifecycle is as follows: gravid females migrate down the colon to the ano-genital region where they lay their eggs and then die. The resultant itching evokes scratching, so that eggs are frequently transferred to the fingers and thence to the mouth where they are swallowed. The eggs hatch in the intestine where the adults mate, and so complete the life cycle.

There are a number of reports of Enterobius vermicularis having been found in various tissues outside the gastrointestinal tract: these were reviewed by Symmers in 1950 . The female genital tract and the peritoneum are the most common sites for ectopic infestation. The parasite has been found in the lumen of the female genital tract and also in the wall, particularly of the Fallopian tube (Smith and Denton, 1928; Jones and Bunting, 1931; Chomet, 1942). The worm or its ova have also been found encapsulated in the peritoneum (Schenken and Tamisiea, 1956; de Ruiter, Rijpstra, and Swellengrebel, 1962), mainly in women in the pelvic area. In the majority of cases, there was a granulomatous reaction around the parasite. The lesions were incidental findings in 18 out of 23 cases having caused no clinical symptoms (Symmers, 1950). The worms probably gain access to the peritoneum via the female genital tract (Goodale and Krischner, 1930; Jung and Carrera, 1960).

Received for publication 30 May 1972.
At the turn of the century there was much controversy concerning the relationship of Enterobius vermicularis to appendicitis. It would seem not to be a cause of appendicitis (Gordon, 1933) but to be a possible cause of 'appendicular colic' (Aschoff, 1913). This is probably the only way it may cause symptoms. Even when it is found deep in the wall of the appendix, there is no inflammatory or fibrotic reaction to the parasite (Gordon, 1933; DuranJorda, 1957).

Intestinal lesions due to the parasite are few and of doubtful significance. In a number of cases they have been associated with ulceration of the colonic mucosa but whether this is a coincidental occurrence or a causal relationship is not clear. Pinworms have been seen to have escaped into the peritoneal cavity through perforations in the intestine (Grigorenko and Timofeev, 1970) and to be buried in the gut wall (Bijlmer, 1946) with no obvious site of entry (Ruffer, 1901). The parasite has also been found in ano-rectal abscesses, in fistulae, and in operation wounds. In all these instances it is probable that the worm migrated into a preexisting defect and was not the cause of the lesion (Symmers, 1950).

Some unusual sites in which Enterobius vermicularis has been found include the lungs, the breast, a leiomyoma of the ileum, the spleen, the ureter and kidney (Symmers, 1950), and the prostate (Symmers, 1957). In the latter two sites there was an inflammatory reaction to the worm.

In summary, it may be said that Enterobius vermicularis is occasionally encountered outside the gastrointestinal tract. Here, it rarely causes any pathological change, and still more rarely does it cause any clinical symptoms. When pathological 
changes are produced in the tissues by the presence of the worm or its ova, they usually take the form of granulomas with or without giant cells and fibrosis. Eosinophils may be present but are not invariable nor is peripheral eosinophilia a regular finding.

We have encountered three patients in whom pinworms were found outside the lumen of the gastrointestinal tract. The pathological lesions are described and their relationship to the clinical symptoms is discussed.

\section{Case Reports}

\section{CASE 1}

A woman of 23 years of age was admitted to hospital as an emergency with peritonitis. At operation, an inflammatory tumour of the sigmoid colon was found and exteriorized. There was a purulent peritonitis due to a perforation of the 'tumour'. Biopsies of the inflammatory tumour and of the omentum were taken at the operation and microscopically these showed fresh haemorrhage, granulation tissue, chronic inflammation, and focally prominent eosinophils. Sixteen days later $15 \mathrm{~cm}$ of the sigmoid colon was removed. The wall of the mid $7 \mathrm{~cm}$ of the specimen was thickened and the serosa covered with exudate. At the centre of this thickened area there was a perforated diverticulum $1 \mathrm{~cm}$ in diameter situated on the antimesenteric border. The mucosa of the colon appeared normal macroscopically and microscopically. Histologically there was an organizing peritonitis and an intense eosinophil infiltrate of the submucosa, muscularis propria, and subserosa. Sections of the diverticulum showed two adult pinworms (Enterobius vermicularis) in the submucosa at the edge of the perforation surrounded by eosinophils (Figs. 1 and 2).

Investigations revealed an eosinophilia in the peripheral blood (total eosinophil count $1452 / \mathrm{cmm}$ ) but no ova or worms were found in the faeces. An uninflamed appendix had been removed four years previously and was found to contain pinworms. No ova were found in the faeces at that time, but Antepar was administered for one week. The patient's recovery was uneventful.

\section{CASE 2}

A woman of 62 years of age was admitted complain-
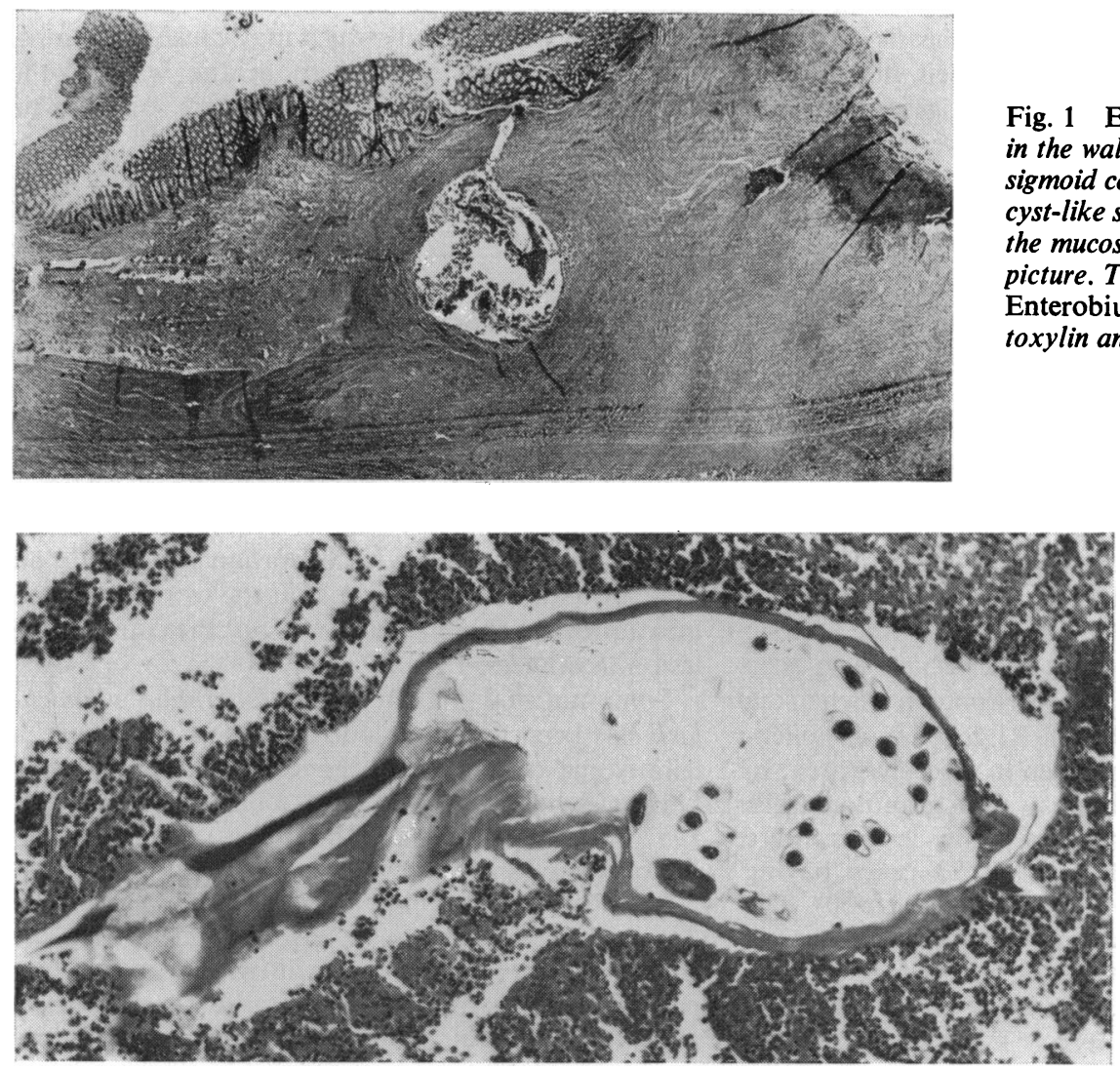

Fig. 1 Enterobius vermicularis in the wall of a diverticulum of the sigmoid colon (case 1). A round cyst-like structure is present beneath the mucosa near the centre of the picture. This contained gravid Enterobius vermicularis (haematoxylin and eosin $\times 2$ ).
Fig. 2 Gravid female Enterobius vermicularis in the wall of a diverticulum of the sigmoid colon (case 1). The worm contains ova, and is surrounded by a florid inflammatory reaction, mainly eosinophils (haematoxylin and eosin $\times 140)$. 
ing of having had abdominal pain, vomiting, and diarrhoea 10 days previously. The symptoms had subsided but she was anorexic and still tender in the right iliac fossa. Other members of the family had had

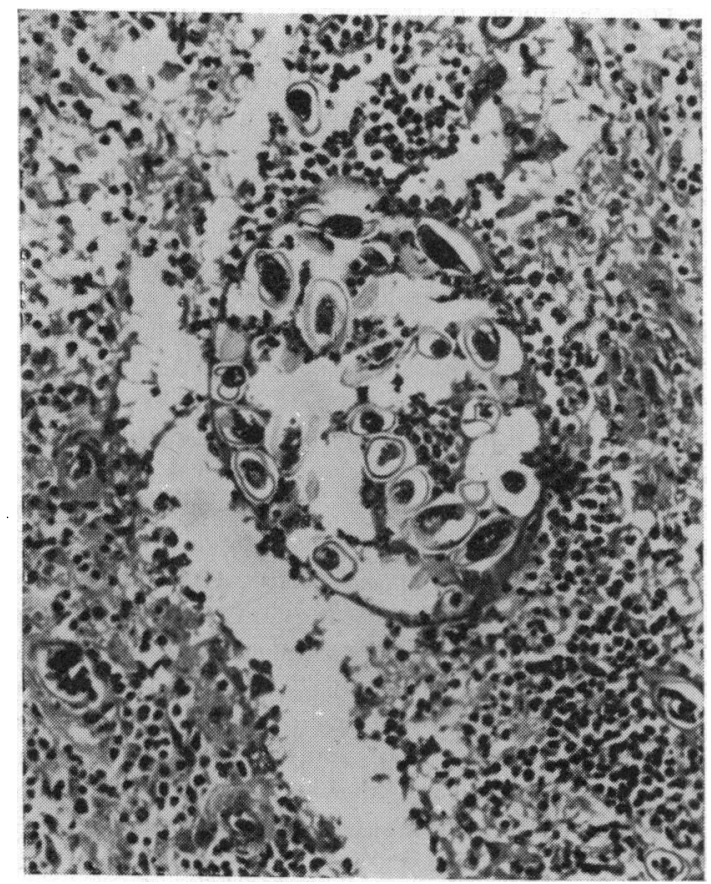

Fig. 3 Enterobius vermicularis in the retrocaecal tissues (case 2). Note the gravid female containing ova and surrounded by an inflammatory reaction. Several ova are lying free in the tissues around the worm (haematoxylin and eosin $\times 100$ ). similar symptoms at the same time but had recovered completely. On examination, a large, hard, tender mass was palpated in the right iliac fossa. Apart from a low serum albumin, investigations, including a barium enema and peripheral white cell count, were normal.

A provisional diagnosis of carcinoma of the caecum was made and the patient was submitted to operation. A large firm mass was found in the wall of the ascending colon, adherent to the anterior abdominal wall. The mass was resected and closer examination showed it to be composed of hard yellow and grey tissue, $5 \mathrm{~cm}$ diameter, situated in the retrocaecal area, in which there was a small lumen, thought to be the appendix. The mucosa of the colon was normal. The retrocaecal tissue showed an inflammatory mass in which a disrupted appendix was embedded. At one point outside the appendix there was a gravid female pinworm containing ova and around which were scattered ova with giant cells (Figs. 3 and 4).

Postoperatively the faeces were examined for ova and worms but none was found. The patient made an uneventful recovery.

\section{CASE 3}

A man of 22 years of age had had an appendicectomy two years previously, following perforation and peritonitis. Unfortunately there was no record of it having been sent for pathological examination. His present admission to hospital was for investigation of loss of weight for the past seven months associated with constipation. A palpable mass was found in the anterior rectal wall, and an intravenous pyelogram showed a dilated right ureter. A biopsy of the rectal

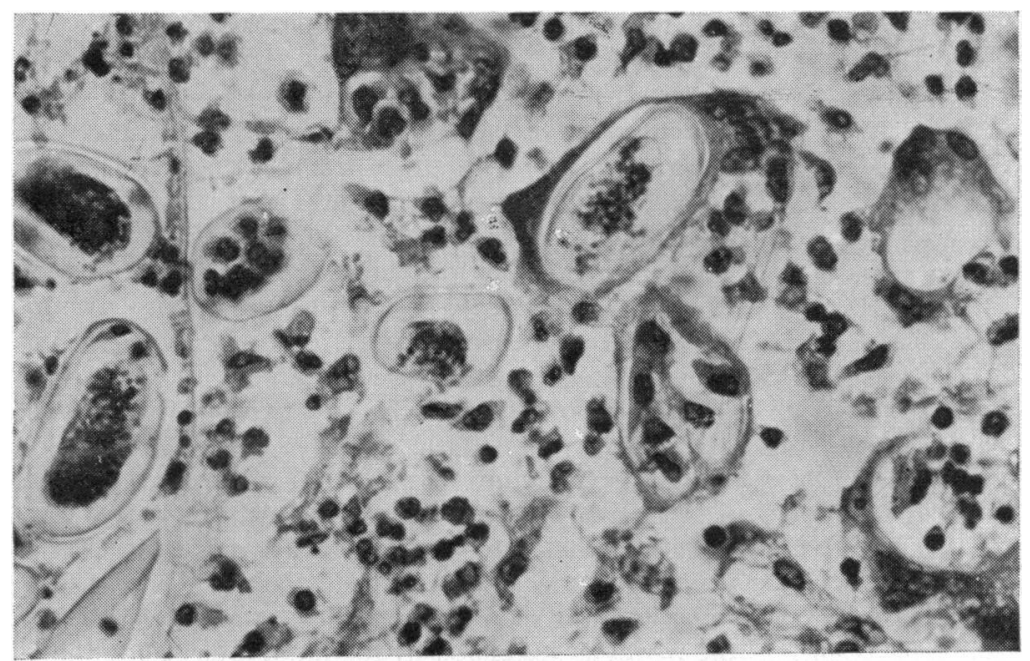

Fig. 4 Enterobius vermicularis in the retrocaecal tissues (case 2). There are ova enclosed within the pinworm, the wall of which can be seen to the left. Escaped ova are seen in the centre and to the right of the illustration. Three of these have giant cells closely applied to their surfaces (haematoxylin and eosin $\times 250$ ). 


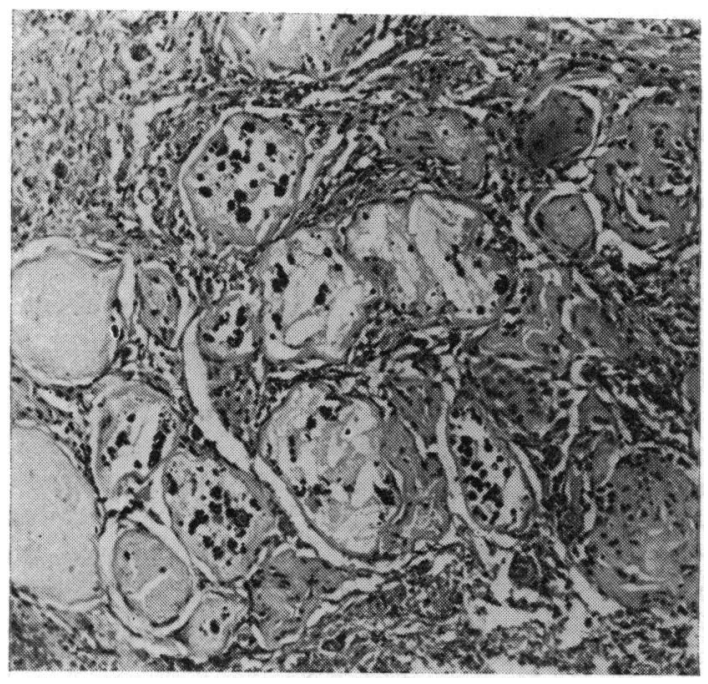

Fig. 5 Necrotic Enterobius vermicularis on the serosa of the sigmoid colon. Several of the round structures show a definite wall, particularly in the upper portion of the figure. The black bodies are probably calcified ova (case 3) (haematoxylin and eosin $\times 140$ ).

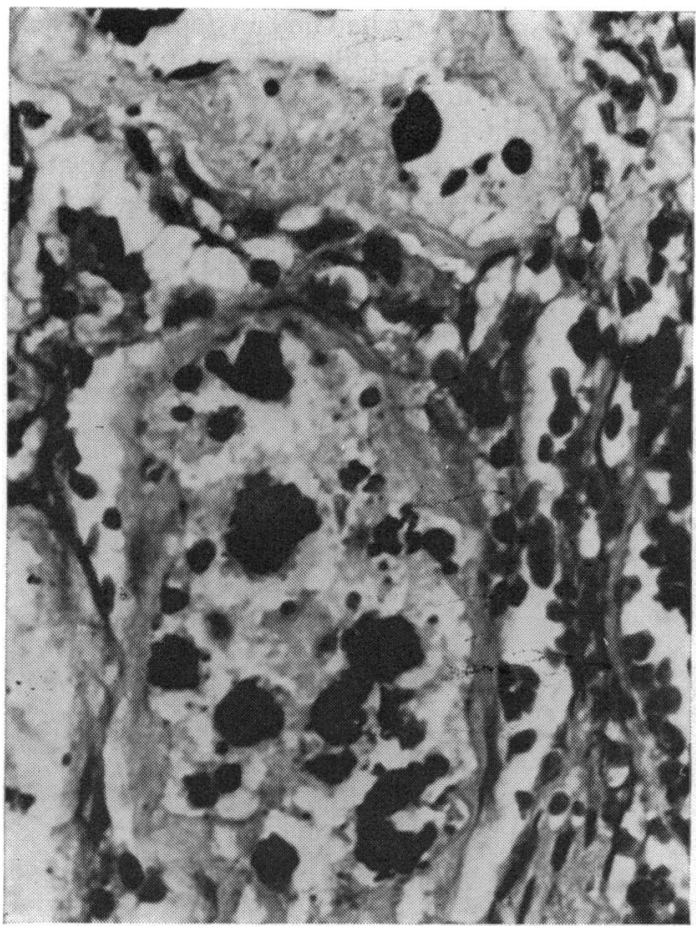

Fig. 6 Necrotic Enterobius vermicularis in subserosa of sigmoid colon. Note the definite wall enclosing black bodies, which are probably calcified ova (case 3) (haematoxylin and eosin $\times 720$ ). mucosa showed focal ulceration and granulation tissue. At laparotomy an inflammatory mass was found in the upper rectum which was obstructing the right ureter and this was resected after the ureter had been freed.

The specimen for pathological examination consisted of $35 \mathrm{~cm}$ of sigmoid colon and rectum. There was a stricture at the mid point due to thickening of the wall by grey tissue and the proximal bowel was dilated. Most of the thickening was present in the pericolonic tissues and subserosa. The mucosa was normal with the exception of the rectum where it showed a cobblestone appearance.

The clinical features and macroscopic appearance suggested Crohn's disease but histological examination showed subserosal fibrosis with foci of acute and chronic inflammation and some eosinophils, with no granulomas. Numerous pink round bodies were present in the subserosa, several showing a definite chitin-like wall (Fig. 5) and some containing calcified foci (Fig. 6). The appearances were interpreted as being an organized peritonitis probably due to the episode two years previously. The foreign bodies were consistent in size and shape with necrotic pinworms, some containing foci of calcification, probably ova. The overlying mucosa of the colon was normal. A microscopic mucosal ulcer was present in the rectum which also showed submucosal chronic inflammation and one aggregate of foreign body giant cells. The changes were thought to be due to Crohn's disease but multiple sections showed no more conclusive features.

\section{Discussion}

Enterobius vermicularis can be identified in cross section by the 'spines' on either side of the body which are the cuticular keel or crest extending the whole length of the body. These were clearly seen in in the worm found in the first patient. The pink structures on the serosa of the third patient were too degenerate to distinguish the presence of lateral spines, but they were the same size and shape as Enterobius vermicularis and many had a definite wall. Calcified foci may have been ova. The ova of Enterobius vermicularis measure $50-60 \mu \times 20$ to $30 \mu$ and are asymmetrical, one side being more convex than the other (Swellengrebel and Sterman, 1961). The ova seen in the first two patients fit this description.

The diverticulum in the colon of the first patient was probably congenital in origin. The pinworm was a gravid female which entered the diverticulum on its way down the colon to the exterior. Much of the inflammation was probably due to the presence of the worm as suggested by the numerous eosinophils, 
not only in the immediate vicinity but in tissue outside the colon and in the peripheral blood. Whether the diverticulum was inflamed before the entry of the worm is not possible to say. However, the patient did have an episode of abdominal pain and vomiting two weeks before her emergency admission, suggesting an episode of diverticulitis, during which the worm was able to penetrate the wall. The increased inflammation caused by its presence may have led to perforation of the diverticulum and subsequent peritonitis. The eggs of pinworms have been found in the wall of the colon, encapsulated between the submucosa and muscularis propria with normal overlying mucosa (Ruffer, 1901) but other cases (Bijlmer, 1946; Gerpt, 1967) have been associated with mucosal ulcers. These probably allowed the worms to penetrate the wall. DuranJorda (1957) has observed Enterobius in all layers of the appendix without any surrounding inflammatory reaction but none of the appendices were entirely normal. These findings support our view that the resistance of the mucosa must first be weakened by disease before penetration by the worm.

In our second patient the presence of the pinworm and ova in the retrocaecal tissues was most likely due to perforation of an inflamed retrocaecal appendix. The presence of the worm may have served to prolong the inflammation leading to the development of a retrocaecal mass and a provisional diagnosis of carcinoma. Such a situation has occurred with other nematodes (Anthony and McAdam, 1972). The presence of necrotic parasites on the serosa of the sigmoid colon of the third patient was most likely due to their escape from the perforated appendix two years previously although we have no proof that the appendix contained the worms. They had become enclosed by fibrosis which had caused stricture of the bowel and intestinal and ureteric obstruction. The appearances simulated Crohn's disease but there was no conclusive evidence of the presence of this condition. Ectopic Enterobius vermicularis on the peritoneum of males can only occur if a part of the intestine perforates and the worm escapes. Live pinworms have been described on the peritoneum after having escaped through perforations in the ileum (Grigorenko and Timofeev, 1970). Unfortunately no biopsy of the perforations was taken so it is not known whether they were due to the worm or some other pathological process.

Live worms in the wall of the appendix appear to be able to live in perfect symbiosis with the tissues, causing no inflammatory reaction (Duran-Jorda, 1957). One of us (G. McD) has observed a worm in a superficial dilated crypt of an appendix with no inflammatory reaction. We have, however, found necrotic worms deep in the wall of the appendices of two patients although they could not be identified as Enterobius vermicularis with any certainty (McDonald and Hourihane, 1970). It is suggested that an inflammatory reaction in the tissues occurs only to necrotic pinworms.

From the present series of cases and the reports of others it would appear that Enterobius vermicularis can only penetrate the wall of the intestine or the appendix if this is diseased. Healthy tissue forms an effective barrier. Its presence on the peritoneum in males can only occur if the appendix (or intestine) perforates as a result of such inflammation. In females, this may occur but the usual route is via the genital tract. If pinworms do penetrate the wall or escape to the peritoneum, they may exacerbate the existing inflammation, causing generalized peritonitis (patient 1), or may give rise to fibrosis which can simulate carcinoma (patient 2) or Crohn's disease (patient 3). Enterobius vermicularis is, therefore, a significant, albeit rare, cause of pathology within the abdomen and should be included in the differential diagnosis of some important abdominal conditions.

\section{References}

Anthony, P. P., and McAdam, I. W. J. (1972). Helminthic pseudo. tumours of the bowel: thirty-four cases of helminthoma. Gut, 13, 8-16.

Aschoff, L. (1913). Appendicopathia oxyurica. Med. Klin., 9, 249-251. Quoted by Symmers, W. St C. (1950). Pathology of oxyuriasis. Arch. Path., 50, 475-516.

Bijlmer, J. (1946). Exceptional case of oxyuriasis of the intestinal wall. J. Parasit., 32, 359-366.

Chomet, B. (1942). Oxyuris vermicularis infection of the wall of a Fallopian tube. Arch. Path., 34, 742-744.

Duran-Jorda, F. (1957). Appendicitis and enterobiasis in children. A histological study of 691 appendices. Arch. dis. Child., 32, 208215.

Faust, E. C., and Russell, P. F., Eds. (1964). Craig and Faust's Clinical Parasitology, 7th ed., pp. 412-416. Kimpton, London.

Gepts, W. (1967). Les granulomes vermineux de l'intestin. Acta gastro-ent. belg., 30 (2), 149-157.

Goodale, R. H., and Krischner, H. (1930). Oxyuris vermicularis in the peritoneum. Arch. Path., 9, 631-634.

Gordon, H. (1933). Appendical oxyuriasis and appendicitis: based on a study of 26051 appendixes. Arch. Path., 16, 177-194.

Grigorenko, G. F., and Timofeev, V. K. (1970). 'Acute abdomen' in perforation of the intestine by pin worms. (Russian) Vestn. Khir., 104 (6), 104.

Jones, W. J., and Bunting, C. H. (1931). Invasion of the Fallopian tube by Oxyuris vermicularis: report of a case. Arch. Path., 11, 229-235.

Jung, R. C., and Carrera, G. M. (1960). Parasitic diseases of the colon, rectum and anal canal: clinical considerations and pathologic manifestations. Dis. Colon Rect., 3, 313-329.

Juniper, K. (1969). Enterobiasis. In Gastroenterologic Medicine, edited by M. Paulson, pp. 511-512. Lea and Febiger, Philadelphia.

McDonald, G. S. A., and Hourihane, D. O'B. (1970). Unpublished observations.

Ruffer, M. A. (1901). Note on the lesions produced by Oxyuris vermicularis. Brit. med. J., 1, 208-209.

de Ruiter, H., Rijpstia, A. C., and Swellengrebel, N. H. (1962). Ectopic Enterobius vermicularis: variations in its pattern. Trop. geogr. Med., 14, 375-380.

Schenken, J. R., and Tamisiea, J. (1956). Peritoneal granulomas due to Enterobius vermicularis: report of a case and a review of the literature. Arch. Surg., 73, 309-311. 
Smith, W. S., and Denton, J. (1928). A case of pyosalpinx caused by Oxyuris vermicularis complicated by torsion of the oviduct. Amer. J. Obstet. Gynec., 16, 205-210.

Swellengrebel, N. H., and Sterman, M. M. (1961). Animal Parasites in Man, p. 310. Van Nostrand, Princeton, N.J.

Symmers, W. St. C. (1950). Pathology of Oxyuriasis: with special reference to granulomas due to the presence of Oxyuris vermicularis (Enterobius vermicularis) and its ova in the tissues. Arch. Path., 50, 475-516.

Symmers, W. St. C. (1957). Two cases of eosinophilic prostatitis due to metazoan infestation (with Oxyuris vermicularis, and with a larva of Linguatula serrata). J. Path. Bact., 73, 549-555.

\section{The July 1972 Issue}

\section{THE JULY 1972 ISSUE CONTAINS THE FOLLOWING PAPERS}

Two types of Zollinger-Ellison syndrome: immunofluorescent, cytochemical and ultrastructural studies of the antral and pancreatic gastrin cells in different clinical states JULIA M. POLAK, B. STAGG, AND A. G. E. PEARSE

Pancreatic alkaline phosphatase and a tumour variant T. W. WARNES, W. R. TIMPERLEY, PAULINE HINE, AND G. KAY

An enteroglucagon tumour S. R. BLOOM

Duodenal involvement in Gardner's syndrome. R. N. MELMED AND I. A. D. BOUCHIER

The effects of humoral agents on the myoelectrical activity of the terminal ileum W. E. WATERFALL, B. H. BROWN, H. L. DUTHIE, AND G. E. WHITTAKER

Immunoglobulin-containing cells in the small intestine during acute enteritis J. SøLTOFT AND B. SøEBERG

Site of the abnormal stimulus of gastric secretion after small bowel exclusion B. BUXTON, A. E. O. WASUNNA, J. SAUNDERS, AND I. E. GILLESPIE

Observations on folate absorption with particular reference to folate polyglutamate and possible inhibitors to its absorption JANET PERRY AND I. CHANARIN
Effect of ornithine alpha ketoglutarate on disturbances of brain metabolism caused by high blood ammonia I. M. JAMES, G. DORF, S. HALL, H. MICHEL, DRAGOSLAVA DOJCINOV, G. GRAVAGNE, AND LINDSAY MaCDONELL

The site of denervation in achalasia SIDNEY COHEN, ROBERT FISHER, AND ARTHUR TUCH

Effect of luminal ions on the transepithelial electrical potential difference of human rectum E. Q. ARCHAMPONG AND C. J. EDMONDS

In-situ and invasive carcinoma of the colon in patients with ulcerative colitis D. J. EVANS AND D. J. POLLOCK

\section{Technique}

A guide wire for rapid jejunal biopsies with the Crosby capsule TONY WICKS AND DAVID CLAIN

Progress report The secretory immune system of the intestine WILLIAM F. DOE

Progress report Hepatic metabolism of drugs R. T. WILLIAMS

Notes and activities

Copies are still available and may be obtained from the PUBLISHING MANAGER, BRITISH MEDICAL ASSOCIATION, TAVISTOCK SQUARE, LONDON, WC1H 9JR, price $87 \frac{1}{2} p$ 